\title{
Why learning space matters: a script approach to the phenomena of learning in the emergency remote learning scenario
}

\author{
Dishari Chattaraj $^{1}$ (D) Arya Parakkate Vijayaraghavan ${ }^{1}$
}

Received: 1 December 2020 / Revised: 31 December 2020 / Accepted: 4 January 2021 /

Published online: 21 January 2021

(C) Beijing Normal University 2021

\begin{abstract}
The study focuses on how the notion of learning space is perceived and experienced by learners in the Emergency Remote Learning (ERL) scenario. In doing so, the lived experiences of remote learners who were abruptly shifted to a completely online learning space due to the pandemic COVID-19 in the Indian higher education system are documented. Online interviews were conducted with eight undergraduate and four postgraduate students of English and Cultural Studies, enrolled at a Southern Indian university, and their responses were explicated using the Interpretive Phenomenological Analysis (IPA) approach. The interviews revealed that the phenomenon of ERL is shaped by dissonance informed by the absence of a familiar learning space. Often the patterns of this dissonance were marked by (1) the perception of learning and learning space, (2) the lack of intimacy in learning and learning space, (3) the negotiations made for learning and the space of learning in ERL, and (4) the challenges to cope with the responsibilities of the ERL scenario. Further, the script approach was applied to analyse the data and the analysis revealed an expansion of the existing internal scripts that were based on previous learning experiences of the learners. The study thus establishes the centrality of space in the process of learning and points out how the lack of a familiar learning space is linked to the absence of internal scripts that considerably impact learning. The study concludes by discussing the possibilities of application of script approach to effectively incorporate the aspect of learning space in new pedagogies and learning models as Blended Learning (BL) and Online Learning (OL) become the new normal worldwide.
\end{abstract}

Dishari Chattaraj

disharij@gmail.com; dishari.chattaraj@christuniversity.in

Arya Parakkate Vijayaraghavan

arya.pv@christuniversity.in

1 Department of English and Cultural Studies, School of Arts and Humanities, Christ University, Bangalore, India 
Keywords COVID-19 - Emergency remote learning $\cdot$ Interpretive phenomenological analysis $\cdot$ Learning experience $\cdot$ Learning space $\cdot$ Script theory of guidance

\section{Introduction}

The declaration of COVID-19 as a pandemic by WHO on 11th of March 2020 impacted the higher education system massively. The sudden closure of schools, colleges, and universities to prevent community transmission resulted in the shift to online, remote, and digital education systems across the world (Rashid and Yadav 2020). While the introduction of emergency e-learning as a crisis-response measure is not relatively new in certain parts of the world (Murphy 2020), such a large-scale transition across the globe has never been documented before. This shift is marred in controversies in India. The immediate closure of 993 universities, 39,931 Colleges, and 10,725 standalone educational institutions affected more than 320 million students in the country (Jena 2020) as only 100 institutions of higher education were allowed to start online classes from the beginning of June 2020. Thus the propagation of digital divide and re-establishment of existing socio-economic hierarchies were raised as the main concerns. While some of the studies from various countries point towards the structural inequalities and the dangers of normalizing emergency e-learning (Gaynor and Wilson 2020), few other works explore the possibilities of such a shift on educational systems (Adedoyin and Soykan 2020; Sepulveda-Escobar and Morrison 2020). In either of the cases though this shift in learning remains a part of discussions, there is hardly any attempt to understand how the shift in space of learning impacts the experiences of learners and the process of learning. The present study, therefore, through a phenomenological approach, attempts to understand the phenomena of learning in Emergency Remote Learning (ERL) by locating it within the learners' perceptions of space. Furthermore, the study uses the script approach to discuss the possibilities of incorporating the perception of lived learning space and experiences in the pedagogy to enable the learners effectively adapt to the changing scenario.

\section{Emergency remote learning}

ERL gained prominence in the context of COVID-19. Identified as one of the many sub-forms of e-learning, it temporarily but completely replaced the conventional educational systems and structures. Historically, e-learning is recognized as an umbrella term and has been perceived as an alternative to conventional education or a complementary to the same (Basak et al. 2018). Literature (Choudhury and Pattnaik 2020) provides evidence of the benefits of e-learning. However, it is acknowledged that the transition from traditional classroom-based learning to e-learning requires significant time and adjustment alongside the availability of resources (Arbaugh 2004). As schools and universities hurriedly shifted to e-learning, problems and challenges started getting reported from around the world. Access 
to resources required to avail e-learning became an issue coupled with the lack of training and standardized models, even in the first world countries (Hobbs and Hawkins 2020). The pandemic thus affected the higher education sector massively (“COVID-19 and higher education" 2020; Green et al. 2020), specifically the students who were at the verge of graduating.

Emerging from the context of the pandemic, the concept of ERL is established in literature (Hodges et al. 2020; Schultz and DeMers 2020). The UNESCO report (“COVID-19 and higher education" 2020) provides five suggestions considering this exceptional teaching-learning situation that are extendable to the higher education sectors worldwide. The suggestions focussed on continuity in teaching, supporting disadvantaged students, documenting pedagogical changes, enhancing digitalization, hybridization and ubiquitous learning, and promoting internal reflection on the renewal of the teaching learning models. Studies conducted to analyse and understand ERL can be traced back to the suggestions. Most of the studies have taken a quantitative approach to understand the impact of ERL on the learning habits of the students (Trung et al. 2020), equitable access to education and online resources (Adnan and Anwar 2020; Jæger and Blaabæk 2020), the security about the future of learning (Chan 2020), and the psychological stress among the learners (Hasan and Bao 2020).

A handful of studies have also been conducted in the Indian higher education context (Bozkurt and Sharma 2020; Kapasia et al. 2020; Jena 2020). These studies have generally been descriptive in nature, discussing the impact of government decisions on education during COVID-19, and the general issues with online learning emerging from the ERT situation (Bozkurt and Sharma 2020; Jena 2020). Kapasia et al.'s study (2020), based on quantitative data $(n=238)$ from graduate and undergraduate students in an eastern Indian state also used descriptive statistics to discuss the characteristics of participants, knowledge and attitude regarding COVID-19, learning status during the pandemic, platforms used for online learning, opinions regarding government decisions in education, and problems related to online learning. Even in a pre-COVID-19 era, studies in the domain of e-learning have always been quantitative in India. They provided empirical evidence for what percentage of students found e-learning useful or were ready for e-learning (Jebakumar 2009; Mehra and Omidian 2011). While the observations made in these quantitative studies are relevant, there is a necessity to document the experiences of the learners to further understand the phenomena of learning in ERL and how the shift to online learning (OL) has impacted the learning process.

As OL becomes the new normal, it is undeniable that in a post-pandemic era, e-learning and blended learning (BL) will become an integral part of the educational system (Lockee 2020). BL aims to incorporate the advantages of both face-to-face learning and e-learning (Graham 2006) by exploring the possibilities to effectively combine both (Wong et al. 2014). Some of the benefits of BL include greater flexibility in terms of costs (Harding et al. 2012), accommodation of a large number of students (Macedo-Rouet et al. 2009), increased motivation and performance (Dziuban et al. 2011), and flexibility and innovation in teaching and learning (Poelmans and Wessa 2015). Studies that discussed the paradigm shift that BL entails in learners' independence and autonomy as well as approaches in pedagogy and curriculum 
design to effectively employ BL are evident in literature (Lai et al. 2016; Wong et al. 2020). However, studies have not elaborately attempted to engage with the mode in which learning space shapes the experiences of learning in BL.

\section{Learning space and experiences}

Historically, there has been a paucity of research on learning space in higher education. Often learning spaces are engaged from an architectural perspective or are conceptualized as a resource to be managed as teaching, learning, and research activities (Temple 2008). A comprehensive understanding of some of the existing research in the area can be gained from the exploratory study by Ellis and Goodyear (2016). Some of the key areas pointed out in this work are the engagement of learning spaces as part of physical formal and informal settings, virtual formal and informal settings, hybrid setting emerging from the integration of physical and virtual settings, tools and artefacts in virtual settings, and the learners' experiences. While, in the Indian context, the conventional understanding of learning space as an infrastructural element promoting equity and learning becomes the focus (Sarin and Dholakia 2016; Raheja and Suryawanshi 2014), there is limited engagement on the experiences of learning as informed and constituted by space and vise versa.

Few of the works that are particularly insightful in engaging with space beyond the conventional perception as a passive setting could be reflected in Furján's (2007) observation on the need to blur the boundaries between the built and the experiences of the built. Thus, space here is perceived as being informed by a complex interweaving of physical, virtual, social, cognitive, and emotional (Melhuish 2011). This perception of space as being mediated by multiple interactions with various elements and varied lived experience (Carp 2008; Massey 1999) further challenges the established perception of space as a passive container. Therefore, the present study engages with space as, "not the setting (real or logical) in which things are arranged but the means whereby the position of things becomes possible" and thereby focuses on space as "universal power enabling them to be connected" (Merleau-Ponty 1962, p. 284).

Drawing insights from Maurice Merleau-Ponty's Phenomenology of Perception (1962), in the paper, space therefore becomes the locus through which the phenomena of learning is explored. The centrality of the space in understanding the phenomena of learning in ERL emerges from the realization that there has been a shift in the space of learning with the onset of the pandemic (Dhawan 2020; Williamson et al. 2020). This focus on space is also significant considering the impetus on effective implementation of BL and understanding the impact of learning space on it. Although an emerging area of study, a few significant works that engage with the notions of future, new, and flexible learning space resulting from this transition in the educational sector can be located in the literature (Benade 2017; Kollar et al. 2014; Saltmarsh et al. 2015). In this context, the study conducted by Kollar et al. (2014) to analyse the impact of new learning spaces by employing the script approach is particularly relevant. 


\section{Philosophical and theoretical understanding}

The research is anchored within the larger theoretical framework of Script Theory of Guidance (Fischer et al. 2013) rooted in the term script inspired from the works of psychologist Silvan Tomkins (Frank and Wilson 2020). Script is understood as procedural knowledge that informs sequences of actions in a recurring event and therefore is regarded as a blueprint or plan for a series of actions. It dictates what should typically happen in a series of actions (Bauer and Fischer 2007). The script approach that the research adopts is based on the experimental study conducted by Kollar et al. (2014) on new learning spaces. Script in the work is understood as an individual, flexible memory structure consisting of components named play, scene, role and scriptlet. Play refers to the existing knowledge of an individual of any particular domain or situation; scene is the knowledge of specific episodes within the play; role is the knowledge of the way an individual acts within an existing scene; and finally, scriptlet is the knowledge of performing specific tasks related to a specific role. The exploratory study observes that learning in unfamiliar situations is challenging for the learners owing to the absence of relevant prior experiences enabling them to effectively re-configure the internal script components. This is insightful to the present study as the ERL scenario is marked by its sudden shift and unfamiliarity. Therefore, the assumption is that the script approach can significantly contribute in understanding the learner's perception of ERL.

The phenomena of learning in the ERL context is primarily marked by a shift in the experiences of learning and space as is pointed out earlier in the paper. An Interpretive Phenomenological Analysis (IPA) approach is adopted in the study to understand the consciousness of experiences (Creely 2018). Developing from the work of Husserl, IPA is theoretically grounded in phenomenology, symbolic interactionism, hermeneutics, and ideography (Smith and Shinebourne 2012). The research draws insights from Heidegger and Merleau-Ponty to make sense of the phenomena of learning. For Heidegger (1962), interpretation is a critical process of understanding and every encounter involves interpretation. Heidegger understands consciousness as not-separate from the world one inhabits but as the formation of historically lived experiences. He believes that human beings experience the world not as they know it, rather through the mode of being-inthe-world (Laverty 2003). This mode of being-in-the-world is the reciprocal interdependence between self, others, and objects that slowly comes to the understanding (Conroy 2003). Therefore, the phenomena of learning in the paper is understood through the learner's interpretations of various encounters that inform their experience of ERL. Thus, through IPA, by specifically seeking the learners to describe, understand, and interpret the phenomena of learning (Tuohy et al. 2013), the essence of the lived experience of ERL was attempted to be understood (Creswell and Poth 2016).

Merleau-Ponty's observation on space as an essential aspect of perception along with the human body adds further dimension to the understanding of space in the study. The research adheres to Merleau-Ponty's (1962) position that there 
can be no absolute distinction between space and things that occupy it and also between the idea of space and the mode in which it is perceived. This perception of space, as constituted by the recursive relationship between spatial and social interactions, becomes the locus through which this study seeks to understand the experience of learning in the ERL scenario.

\section{Methodology}

\section{Research questions}

Emerging from the understanding generated and the gaps identified in literature, the present study thus seeks to explore the following research questions:

(1) How is the phenomena of learning in ERL experienced by the learners?

(2) How does the perception of learning space impact the phenomena of learning in general and within the ERL scenario in specific?

(3) What are the implications of sudden spatial shift on the learning process and the learner?

(4) What are the implications of such a sudden shift within the context of higher education?

(5) How can the script approach be utilized to understand the learning process and thereby enable effective transition to BL in future?

\section{Study design}

IPA as an approach is understood as valuable when examining topics which are complex, ambiguous, and emotionally laden (Smith and Osborn 2015). As reflected in the literature, the area discussed requires such attention primarily because of the paucity of qualitative modes of enquiry on the experiences of the learners (Symeonides and Childs 2015; Garip et al. 2020) and the complexities brought about by shifts in learning space. Thus, keeping in mind the nature of the study and the heterogeneity which the essence of experiences might represent, semi-structured interviews comprising open-ended, non-directive questions (Moustakas 2011) were chosen to be utilized for the study. The questions were constructed, reviewed, and revised by the investigators. The general questions used in the interviews are presented in "Appendix 1".

\section{Recruitment}

Ethical approval for the study was granted by the Ethics Committee of the Host University. The participants were final-year undergraduate and postgraduate students who were at the verge of completing one semester in the remote learning setup and had joined physical classes for one or more academic years in the university before shifting to the ERL mode. It was anticipated that the learners who had the experiences of physical classroom space and e-learning space while being affiliated to the 
same university in the same programme would add valuable insights to the study as they would be able to reflect and engage in a comparative analysis of their learning experiences emerging from their occupation of variable spaces. Further, attempts were made to include a representative number of learners from both undergraduate and postgraduate levels as it was anticipated that the process in which learning is understood and practiced would be influenced by the level of study and specialization of the participants.

\section{Participants}

Twelve students volunteered to participate in the study among which four were final-year postgraduate students mastering in English and Cultural Studies and eight were final-year undergraduate students majoring in English Studies. While research shows that there is no right sample-size in phenomenological studies (Smith and Shinebourne 2012), Mastel-Smith and Stanley-Hermanns (2012) point out that the sample-size should be between 4 and 10 participants. However, they add that the sample-size should be decided depending upon the context and the richness of data collected. Since the essence and experiences of lived spaces form the core of this study, attempts were made to include participants from diverse demographics across India. "Appendix 2" presents the participants' demographic characteristics; it provides information on the participant's location during ERL, age, identified gender, level of study, number of family members in the house they occupied, and the availability of an individual study room. All the names were replaced with pseudonyms to protect the participants' identities during transcription by the first author.

\section{Data collection}

The study involved pre-interview questionnaires and individual semi-structured, in-depth interviews. The questionnaire was emailed to the participants individually and was used to obtain informed consent and to gather information on their profiles. The interviews were conducted and recorded through Google Meet in October 2020. Both the research investigators were present during the interviews and while the interviews were led by one investigator, the other investigator raised questions towards the end to gain further insights on the experiences of the learners. The average length of interviews were $30.66 \mathrm{~min}$ and they were transcribed verbatim before being explicated in the study.

\section{Data explication}

The data was explicated from the learners' accounts in the following way: (a) interview transcripts were thoroughly read multiple times; (b) exploratory comments were made and elaborate discussions were conducted to recognize and organize the emergent patterns; (c) attempts were made to define the patterns and establish inter-relationships among them; (d) the patterns were organized and attempts were made to keep the meaning and essence of the participant's experiences (Symeonides and Childs 2015). Adherence to the four broad principles of sensitivity to context, 
commitment and rigour, transparency and coherence, and impact and importance was made, to address the issues of validity and reliability (Yardley 2000 as cited in Garip et al. 2020).

\section{Results}

The interviews revealed that the phenomena of learning in ERL is shaped by the experience of dissonance informed by the absence of familiar learning space and a shift which prior studies report as "disruptive, circuit-breaking, turbulent, or transformative" (Green et al. 2020, p. 1309). Further, the experience was governed by the feeling of temporariness and the hope that things would go back to normal (Chan 2020). Some of the patterns emerging from the interviews are discussed below.

\section{The perception of the learning and learning space}

In the accounts all the participants expressed fond memories of a familiar learning space that is lost owing to the shift to ERL. Interestingly all of them associated the presence of peers, accessibility to tools and resources, the structures like classroom and library, and certain activities performed, like discussions, within these structures to the perception of their ideal familiar learning space. Some of the accounts that clearly resonates this notion are documented here:

Personally, I would prefer the university learning space, because then I am free to discuss everything that I want. And there are a lot of friends, you can talk to who you want, you don't have any stress. And then you have very different opinions about the same subject. So you just listen to them, and you put forward your own opinion. So it becomes a very interactive session. (Saira)

Also, in a classroom suppose, you have to make a particular point, and there is always, it is very easy for someone else to maybe, support you for something, or for that point, or you can have very nice discussions. (Reet)

Okay, so when I, when I talk about the classroom space, I also include all the parts of college that we used to have discussions in, I mean, we used to get taught in class, but sometimes we took those discussions outside to places like Nandhini (cafe) or pitstop.. (Jade)

For Saira, Reet, and Jade, the familiar learning space is perceived through the memory of class discussions along with peers and other occupants of the space. It is notable that these activities are not just restricted to formal structures like classrooms and libraries but are also extended to informal spaces like cafes. Further the classroom space is described by some of the participants using the adjective proper and thereby perceiving the space based on specific activities which are generally understood as conducive for learning. It is evident from the accounts provided below that the learning and the learning space like a classroom is invariably shaped by the experiences and perceptions of each other: 
I think for me, it has to be offline, like in a proper classroom, with, you know, like we do at college. I think that's so much better. Like after seeing all this I just think that was so better. And I can't ask for more at this point. (Faiza)

I prefer a classroom because yeah because I think it's a proper learning space... I think it reminds me of behaviorism because when I sit in a class, I automatically get the urge to study or make notes and note notes and pay attention and all but but I'm in my room, there's no one to tell me what to do.. (Prital)

Prital's account of habitual practices in the classroom adheres to the conventional notion of classroom as a disciplined space, controlled and monitored by an authority. This perception of classroom space is also reflected in the words of Mala, a postgraduate student. While she points out the absence of disciplinary practices in ERL, she also suggests possible modes through which disciplinary practices can be restored in the current scenario. Mala's perception of learning space and learning through the disciplinary practices is evident in her account:

Maybe we should make the students involved much by giving them some presentations of slides and, like, usually in classroom space, what we do: we give seminars to make them involved. And most of the time what I have witnessed is, like many people, even sometimes when I have some (other) work just (switch) on the class. And we (simultaneously) do some (other) work. We should find some means to, like we should keep them occupied.. they should compulsorily (switch) on the video.

Few participants also identified library as a space of individualized and focussed learning:

I missed our library... library was a space that personally helped me get a lot done. It's the whole ambience where everybody's focused on what they want to do, plus, you, when you go to a library, you already go with a mindset that I'm going there to get this, this done or read this much, and then come back. (Pahal)

It would be the library because.. it's like learning space, where everyone's just there to study or to read or to do something. It's a very quiet space. (Sargun)

Evidently, the memory of previous learning and familiar learning space significantly informs the experience of ERL scenario. Here the notion of the familiar space and learning is informed by both collective and individual experiences and perceptions. The sense of loss, absence of familiar learning space, and dissatisfaction with the current learning scenario is largely reflected in all the accounts.

\section{The lack of intimacy in learning and learning space}

The current learning space is perceived by the participants with a sense of temporariness and general belief that things would come back to normalcy as is articulated by Pahal: 
I think most of us are looking at this as something temporary. If you go back to the, the old setup or the physical setup of a class. I think personally I would, even though I like how it is going on right now, I'd be relieved because then there's a sense of familiarity. That tikh hain (it's alright) things are back to as they were.

Along with the sense of temporariness all the participants associated the feeling of strangeness and lack of familiarity with the experiences of learning and learning space in ERL. Most of them participated in ERL from their homes, which is conventionally perceived as personal, comfortable, familiar, and intimate. However there was a general sense of uneasiness that is documented below:

So if I'm attending a class, and somebody's sitting with me, not my classmates, because I'm used to my class with somebody else, or not somebody from library because I'm used to those faces being there. But let's say if my mom is sitting in front of me, then I would not be very comfortable attending. (Pahal)

Small, congested, suffocating sometimes, because I am the one who suffocates it, because with all the doors and windows closed, just to open but it becomes quite noisy sometimes. So, that's suffocating and nothing much to say about it more than that. (Taksh)

Because everything happens in the same room, right... I have been here. I have been in my room alone since the past seven months.. I can't communicate with people, I can't, there's no space for discussion.. it actually affects your mental health. But you know, even the offline classes, we read something, even if it's a novel, or if we talk to a new person, there was always a space for communication. There was always a space for discussion. And that was a two way process. But this is just a one way process... (Salim)

The sense of loss and monotony predominates these accounts and often the dissatisfaction gets registered through the comparisons with their previous experiences before the shift to ERL. Also, the difficulty in communication in the ERL scenario enabled by digital and ICT tools is reflected in the accounts provided:

Yes, everybody's hidden behind the screen so you can't see their facial expressions.. I think teachers are more accessible. I think this is pretty much an irony because right now you just can text, send a text and get your things sorted. But the teachers were just more accessible, you could go and you could sort things out in person. But I don't know, with the technology in between, it just seems.. you're not able to communicate properly. (Sargun) .. I miss sitting with my friends and studying. I missed the class discussions, which used to happen, because I feel like they used to be more engaging. And on a video platform, it is true that more comments come in, and more people join the discussion. But somehow it feels very disconnected... It does not feel very real... It's easier to raise doubts in class than the online platform... this kind of an interaction is not possible in the online space... 
doubt solving and peer support becomes.. more better in the classroom space as compared to an online space... (Prital)

As pointed earlier, the lack of intimacy observed by the participants is governed by the memory and perception of learning and learning space before the shift. The words not real and disconnected were used by the participants to describe the experience of ICT enabled ERL. Though bandwidth and internet connectivity play an important role in facilitating ERL, especially since facilitators and participants switch off their videos to avoid lags, evidently the concerns of the participants were not just restricted to these factors. Also two of the participants were appreciative of certain aspects of ERL. While Taksh felt that the hands-up icon introduced by online platforms would enable better communication, Sargun discussed the dismantling of seating-hierarchy by being at equidistance to the facilitator. In either case, the familiar classroom space and experiences in the space became the point of comparison.

\section{Negotiating learning and the space of learning in ERL}

All the participants revealed a constant struggle in their attempt to negotiate between the experience of ERL and their experience of learning in the familiar learning space. All the participants used words like my room, study room, computer room, or workspace to refer to the learning space or spot in the ERL scenario. The description of the space while is heterogeneous, it is enabled by similar objects and learning tools like laptops, study-tables, chairs, desks, bookshelves, and books that are an integral part of the conventional perception of learning space. The struggle to recreate the room/spot based on their perception of learning and space is often based on the existing structures as is evident in the accounts:

So I made many... I should call fresh starts each time. Especially when I came, I used to like, pile up all my books together, like in a stacked manner so that it looked a little bit like an organized desk space... I do it every now and then I get this sort of phase when I clean up my desk and try to look organized and stuff, but it still isn't the same, I should say... So I try as much as possible to stay at the table. Because if I'm at the table, then I'm fine, I'm sitting upright, the laptop is in front of me. I try not to join from my phone, if I join from my phone, I tend to walk around the house, go sit on the couch or something, then that entire, you know, thing is lost, I can't concentrate I've tried switching off data on my phone till the end of the class...But if I succumb to some days when I want to join through phone and sit on sofa or something, those days are not great. (Jade)

..I have a small whiteboard, so that we will just write and keep what are the things to be done or what isn't. And I have a shelf full of books.. I have a table for study and mostly it will be filled with books and laptops, all the study (related) things will be there and I just have a cupboard to keep all the stuff. So, that room will always be pleasant. I will try to keep that room clean when compared to others... this room for, like, it will be always arranged.. my study room will always be perfect... we have an iron stool to sit. We won't sleep. We 
don't have a bed, just I have a table, and, like, even if two to three members if they come, they can sit so then we have a table. (Mala)

The necessity for structure and order is evident in their habitual ritualistic acts of arranging, planning, cleaning, and rearranging. The practice of maintaining a particular posture and sitting on the study-table during the learning process emulates the images of formal classroom-like learning space. In certain cases, the perception of learning is informed by the sanctity of learning in the cultural context and the mandates of the formal setup of the past. Niya observes:

I tried to get up at least 15 min before the class.. I wake up, I brush and I freshen up, and I walk around a little bit so that I'm awake. This is for mainly morning classes, and then I sit in the workspace for like five minutes before classes because that's when everybody starts logging in, and then I use my laptop and just enter.

Also, the observations of participants in terms of the occupants of the household learning space and its impact on learning is significant to note:

..especially with my older sister, because with her course, it's like she needs to get a lot done in a day. And if I see her laptop constantly on something, so it does give me some sense of that focus... and motivation. (Pahal)

I mean, even after our class gets over the first thing I do is I go to a WhatsApp group and I'll text like you know what let's discuss whatever was studied. Because I just cannot just take something that's been taught.. I do try to interact with class and everything but it's not that fun. I do need someone right next to me. That's why it's so easy for me to study with my grandmother, because she's next to me. I know that even though she doesn't get it, it's easier for me because the moment I hear something my brain will think of something and I just need to follow. (Ahana)

In both the cases there is an overlapping of the familiar learning space with that of the household learning space. Pahal and Ahana perceived the other household inhabitants as motivators enabling learning, thereby attempting to negotiate the loss of the peer learner in the ERL scenario.

\section{The challenges to cope with the responsibilities of the ERL scenario}

The accounts given below document some of the challenges observed by the participants in the ERL scenario:

..when the classes started, I was in Kashmir. But then my dad had Corona and my sister and brother also had it afterwards, then mom and I had to go to Kargil. And dad was hospitalized because the situation was not that great. And once they recovered, we came back to Srinagar. And we thought like things would be normal. But then my sister had an accident. And since then, I've been at the hospital. And before her surgery, we had to come to Delhi. (Faiza) 
Actually, I live alone, like, $50 \%$ of the time, because my mom and my brother have to go out for business in the city. So like, I live in a very small town. The internet is not good. The weather is not good... And, yeah, I normally have to look at the house. But my mom has like workers around also, like, just nearby, so I have to look at them also. And I have to cook for myself... here (university) you don't get the stress and, and you won't have whatever status you have at home, as well as whatever, elderly or owner or something, you don't have to act in that manner. (Sargun)

Um, because every time my papa always speaks loud I mean, that tone of voice, but at times I will be concerned if there's a fight going downstairs, or there's an argument going downstairs. (Salim)

..my father and I have to do all the work because during the quarantine, the maids are not coming... So it becomes really hectic for me to manage my classes with all the household activities... there is my grandmother who gives me the taunt $k i$ (that) you are always sleeping, you're not doing anything. Your father has to do everything. (Saira)

As revealed in the accounts, the experiences were heterogeneous and intersectional than being defined by a singular identity position. The participants were conscious of their class privilege in terms of accessibility yet challenges in connectivity remained mostly consistent. Some geographical locations accentuated the trouble to access the internet as is reflected in the accounts of Faiza and Sargun. For Faiza, the medical situation at home due to the pandemic and otherwise, impacted her learning. The resultant spatial shifts from Kashmir to Delhi further made the experience of ERL highly stressful. For Sargun residing in the North Eastern state of Sikkim, the added responsibilities of being at home alone, hindered her access to a conducive learning space. For Salim residing in the Southern Indian state of Kerala, the domestic conflicts considerably interfered with his learning process. And, for Saira residing in the Eastern Indian state of Chhattisgarh, her gender identity in a traditional Indian household became a barrier in learning. Further, the learners grappled with challenges emerging from the changing process and needs of learning of the ERL scenario as is observed below:

I feel like I'm not very good with time management. So that is one problem that I face. It's about trying to be more productive but not being more productive. (Prital)

..because I have more time now I am finding it difficult to manage time because, so, for me, so I have realised one thing I am struggling at research, which is affecting my dissertation. So I end up spending a lot of time doing that and then I struggle to make up time to do my asynchronous task or study for the classroom activities. And also because maybe I am at a home set up, there is a certain amount of you know procrastination that is happening. (Reet)

..we have to take the trouble to find, I mean, if we want extra additional resources, and we don't like have the liberty of right away approaching the teachers and stuff. I mean, also, instead of like asking on the spot, we will surely get to like, look, we learn to look for things ourselves. But in general, 
yeah. I mean, does it make us more independent? Yeah, I mean, yeah, I guess in one way. Yes. I haven't thought of it before. (Jade)

I think it's more responsibilities for us than we would have ever done before in a university space. I am in control of how I schedule my day. I think it gives me a little more motivation. Now, when I think I was paying more attention to classes because I could control it, despite the distractions I think I was trying to get over these distractions and trying to get there and I feel like I did pay a lot of attention. (Niya)

The undergraduate students Prital, Reet, and Jade struggled with the responsibilities and autonomy in the ERL scenario. Niya, another undergraduate student while making similar observations expressed openness to explore the possibilities offered by the shift. However postgraduate students Taksh and Pahal, were appreciative of the autonomy and also revealed their own modes of negotiations with the shift.

I've made some changes in the way I go about things, or the way I plan my things. And I think I would want to continue with the planning aspect that I've brought in, in the process of my own learning. Because in the original, I keep going back to the word original, but in the former-setup it was, the structure was given, and I would plan according to it, but right now, I made my plans and try to fit the structure in it, if that makes any sense. (Pahal)

So, since the class hours (synchronous) are reduced right now, I would not say that my learning has also reduced.. but it is completely opposite, because we are given the time to read the articles and then when we come to the next class we are supposed to discuss on the same, makes the class more engaging and more and more understandable discussions. So, learning has increased in such a kind of way of teaching. (Taksh)

Pahal's usage of the word original followed by the immediate replacement with former-setup clearly vocalizes the sense of dissonance experienced by all the participants. While most of the post graduate participants were appreciative of the flexibility in ERL scenario, Mala and the undergraduate students were rather sceptical. Further Mala responded to the changes by suggesting modes to replicate conventional learning in ERL, as is discussed earlier.

\section{Discussions}

The patterns emerging from the accounts reveal that the phenomena of learning in ERL is highly informed by the memory of the learning and learning space. This is similar to that of a flexible memory structure in the script approach (Kollar et al. 2014). Nevertheless, these memory structures are not homogeneous or static but are highly flexible and fluid based on the internal scripts of each participant. However, there are patterns which are similar based on cultural contexts and normative notions of classroom spaces and learning. A visual representation of the internal script as is emerging from the accounts is presented below (Fig. 1). 




Fig. 1 Recollected internal script

As the figure indicates, the accounts reveal that the participants adhere to conventional scriptlets informed by normative roles of the students in the educational system. This adherence emerges from the practices of the structured educational system of which the participants were a part. These practices are shaped by the presence of a physical classroom with the instructor at the centre operating as the controller and disseminator of knowledge in front of the students who are recipients of the knowledge and are peer supporters who conform to the formal codes of conduct. Interestingly, in the conventional system, the learning space is merely understood as a passive infrastructural setting (Sarin and Dholakia 2016; Raheja and Suryawanshi 2014; Temple 2008). However, the accounts reveal that the space actively informs and influences the internal scripts constructing and determining the roles of the learner and the phenomenon of learning (Merleau-Ponty 1962).

The ERL scenario, as observed earlier in the paper, is informed by the absence of a physical learning space and a spatial shift. The participants' accounts reveal that it is the existing internal scripts that they attempt to adhere to even when there is a shift in space and an absence of the familiar learning space. As observed by Kollar et al. (2014), when something is unusual, there is a discrepancy between the participant's employed internal script and the current experience of learning resulting in "expectation failure" (p. 4). This is clearly revealed in the accounts of the participants, a visual representation of which is presented below (Fig. 2).

The dissonance between the formal and informal scenes is marked by the perception of space in the ERL situation as a space of learning as well as a household space. While the empirical studies often engage in highlighting the digital divide based on aspects of accessibility (Adnan and Anwar 2020; Jæger and Blaabæk 2020), the experiences of the ERL go beyond identity markers of class and geographical locations. The experiences within the household-informal scene are thus heterogeneous and intersectional. Learning in the ERL space, as visualized in the figure, is informed by the constant struggle to shift between the heterogeneous roles that participants have to simultaneously perform in the situation. The general sense of dissatisfaction resulting from this struggle leads to trigger either a "search for an 


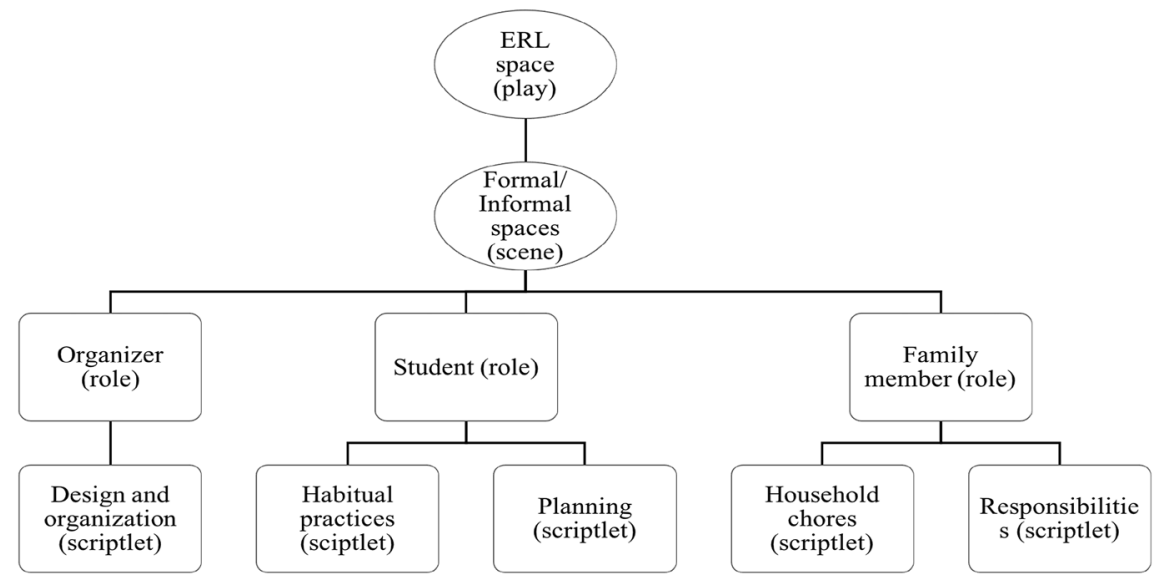

Fig. 2 Negotiated internal script

alternative internal script (or alternative internal script components) to make sense of the situation or yield an expansion of the employed internal script" (Kollar et al. 2014 , p. 4). While the employment of alternative scripts were not clearly indicated in the accounts, the expansion of the internal script is evident in case of the participants. These expansions were influenced by the habitual practices that the participants adopted based on the normative roles of students that they were familiar with in the past. And, though self-directed and independent learning contributed towards effective e-learning or blended learning (Garip et al. 2020; Wong et al. 2020), the recognition for these attributes relatively remained absent in the participant's accounts.

The script approach identifies that the expansion stage leads to a possible repeated deviation from the original internal script thus resulting in the "development of a new internal script component, which is in essence a process of cognitive change, i.e. learning" (Kollar et al. 2014, p. 4). In the ERL scenario, such a cognitive change has not been achieved primarily because of the unplanned and abrupt nature of the shift (Hobbs and Hawkins 2020). If BL becomes an integral part of higher education (Lockee 2020), interventions are required in order to provide the learners with model external scripts and thereby provide them scaffolds to effectively adapt to changing educational scenarios.

\section{Conclusion}

The study thus develops insights on the phenomena of learning in the ERL scenario by documenting and analysing the lived experiences of the learners introduced to ERL as a crisis-response measure to COVID-19. The accounts reveal that the learners experience a sense of dissonance informed by the sudden spatial shift to OL and the realization that the familiar learning space, primarily marked by settings like university space and classroom space, is no longer accessible in the current scenario. 
The memory of previous experience of learning in an offline scenario here shapes the perception of learning space thereby making it challenging to cope with the sudden spatial shifts. The centrality of space observed in the study points at the limiting nature of conventional engagement with space as a passive setting and emphasizes on the need to engage with space in a more dynamic way in the contemporary education system.

In an era where the educational sector is exploring the possibilities of OL and BL, the observation on the significance of space in shaping the experiences of learning is pertinent. The insights gained through the application of script approach is particularly relevant in this context to understand the requirements of the learners and enable them to adapt to new learning spaces and innovative modes of learning. Interventions in form of external scripts through pedagogical and design practices offer possibilities to support this transition effectively though further explorations are required in the area. Here, it is also important to note that though the explorations of the present study are specific to the time frame of ERL, the implications of the study are relevant to the future developments and innovations in the educational sector.

The study, while provides a rich insight into the experiences of the learners in ERL, the identification of similarities in patterns to develop a dominant internal script could be considered as a limitation. However, such a scenario is unavoidable considering the nature of the study and the context of its application. The nature of the study further justifies the number of participants which otherwise can be seen as highly limiting. Furthermore, the demographic diversities among the participants in terms of their geographical location, level of study, identified gender, number of cooccupants in their house, and accessibility to individual study rooms during the ERL period add a certain degree of credibility to the study. The study thus argues that unless there is focussed engagement with learning space in new pedagogies, learning models, and learning tools, the transition to OL and BL envisioned in the educational sector is limited, especially in a world where digitality is the new normal.

Acknowledgements The authors would like to thank the Ethics Committee of the Host University for granting permission for the study and the participants for voluntarily taking part in the study.

\section{Appendix 1: Interview questions}

(1) Have you done e-learning before the pandemic?

(2) Describe a typical day when you do online classes.

(3) Where are you currently located? Is this the same place from where you are joining online classes?

(4) Can you describe the place in which you live and attend your classes from?

(5) Can you describe the room in which you learn?

(6) Do you share the room with anyone? How does sharing a room influence your learning?

(7) How do/did you identify your learning spot? How have you arranged your learning spot? 
(8) What kind of arrangements did you make when you were informed that you will have online classes?

(9) How do you usually attend synchronous classes? (Body posture, dressing, simultaneous activity).

(10) Are there any external factors like noise, smell, movement, etc. that impact your learning? Do you want to share any particular incident from your recent experiences?

(11) What responsibilities/chores do you have at home and do they become challenging while attending synchronous hours?

(12) Does your identity impact your learning experiences in online setup?

(13) Did you arrange your time/routine to accommodate the learning requirements of online classes?

(14) What is your idea of a good learning space?

(15) Can you tell us some of the things which you miss about your classroom space? Do you want to share any particular incident from your recent experiences?

(16) What are some of the things you like about your current learning space and why. Do you want to share any particular incident from your recent experiences?

(17) Do you like e-learning? What do you think are the benefits?

(18) Do you think your present experiences of e-learning would change the way you would learn/participate in the learning process once we go back to campus? If so, how?

\section{Appendix 2: Participants' details}

\begin{tabular}{|c|c|c|c|c|}
\hline $\begin{array}{l}\text { Participant } \\
\text { (duration of } \\
\text { interview) }\end{array}$ & Current location & Age, identified gender & Level of study & $\begin{array}{l}\text { Number of mem- } \\
\text { bers, own study } \\
\text { room }\end{array}$ \\
\hline Salim (30 min) & Alappuzha, Kerala & 23, Male & Masters & 3, Yes \\
\hline Mala (34 min) & Vellore, Tamil Nadu & 21, Female & Masters & 6, No \\
\hline Taksh (38 min) & Erode, Tamil Nadu & 21, Male & Masters & 3, Yes \\
\hline Pahal (34 min) & $\begin{array}{l}\text { Bhopal, Madhya } \\
\text { Pradesh }\end{array}$ & 22, Female & Masters & 5, No \\
\hline Jade (37 min) & $\begin{array}{l}\text { Thiruvananthapuram, } \\
\text { Kerala }\end{array}$ & 20, Female & Undergrads & 4, Yes \\
\hline Prital (31 min) & Bhubaneshwar, Odisha & 20, Female & Undergrads & 3, Yes \\
\hline Reet (23 min) & Kolkata, West Bengal & 20, Male & Undergrads & 4, No \\
\hline Ahana (30 min) & Jaipur, Rajasthan & 20, Female & Undergrads & 4, Shared room \\
\hline Faiza (32 min) & Srinagar, Kashmir & 20, Female & Undergrads & 6 , Shared room \\
\hline Saira (25 min) & Bilaspur, Chhattisgarh & 20, Female & Undergrads & 3, No \\
\hline Sargun (25 min) & Mangan, North Sikkim & 20, Female & Undergrads & 3, Yes \\
\hline Niya (29 min) & Bangalore, Karnataka & 20, Female & Undergrads & 4, Yes \\
\hline
\end{tabular}




\section{References}

Adedoyin, O. B., \& Soykan, E. (2020). COVID-19 pandemic and online learning: The challenges and opportunities. Interactive Learning Environments. https://doi.org/10.1080/10494820.2020.1813180.

Adnan, M., \& Anwar, K. (2020). Online learning amid the COVID-19 Pandemic: Students' perspectives. Journal of Pedagogical Research, 2(1), 45-51. https://doi.org/10.33902/jpsp.2020261309.

Arbaugh, J. B. (2004). Learning to learn online: A study of perceptual changes between multiple online course experiences. The Internet and Higher Education, 7(3), 169-182. https://doi.org/10.1016/j. iheduc.2004.06.001.

Basak, S. K., Wotto, M., \& Belanger, P. (2018). E-learning, M-learning and D-learning: Conceptual definition and comparative analysis. E-Learning and Digital Media, 15(4), 191-216. https://doi. org/10.1177/2042753018785180.

Bauer, K., \& Fischer, F. (2007). The educational research-practice interface revisited: A scripting perspective. Educational Research and Evaluation, 13(3), 221-236. https://doi.org/10.1080/13803 610701626150.

Benade, L. (2017). Is the classroom obsolete in the twenty-first century? Educational Philosophy and Theory, 49(8), 796-807. https://doi.org/10.1080/00131857.2016.1269631.

Bozkurt, A., \& Sharma, R. C. (2020). Emergency remote teaching in a time of global crisis due to CoronaVirus pandemic. Asian Journal of Distance Education, 15(1), i-vi.

Carp, J. (2008). "Ground-truthing" representations of social space: Using Lefebvre's conceptual triad. Journal of Planning Education and Research, 28(2), 129-142. https://doi.org/10.1177/0739456x08 324685.

Chan, N. (2020). Pandemic temporalities: Distal futurity in the digital Capitalocene. Journal of Environmental Media, 1(2), 13-21. https://doi.org/10.1386/jem_00034_1.

Choudhury, S., \& Pattnaik, S. (2020). Emerging themes in e-learning: A review from the stakeholders' perspective. Computers and Education, 144, 103657. https://doi.org/10.1016/j.compedu.2019.10365 7.

Conroy, S. A. (2003). A pathway for interpretive phenomenology. International Journal of Qualitative Methods, 2(3), 36-62. https://doi.org/10.1177/160940690300200304.

UNESCO-IESALC. (2020, April). COVID-19 and higher education: Today and tomorrow. UNESCOIESALC. http://www.iesalc.unesco.org/en/wp-content/uploads/2020/04/COVID-19-EN-090420-2. pdf.

Creely, E. (2018). 'Understanding things from within'. A Husserlian phenomenological approach to doing educational research and inquiring about learning. International Journal of Research and Method in Education, 41(1), 104-122. https://doi.org/10.1080/1743727x.2016.1182482.

Creswell, J. W., \& Poth, C. N. (2016). Qualitative inquiry and research design: Choosing among five approaches. Thousand Oaks, CA: Sage Publications.

Dhawan, S. (2020). Online learning: A panacea in the time of COVID-19 crisis. Journal of Educational Technology Systems, 49(1), 5-22. https://doi.org/10.1177/0047239520934018.

Dziuban, C., Hartman, J., Cavanagh, T. B., \& Moskal, P. D. (2011). Blended courses as drivers of institutional transformation. In Blended learning across disciplines: Models for implementation (pp. 17-37). IGI Global. https://doi.org/10.4018/978-1-60960-479-0.ch002.

Ellis, R. A., \& Goodyear, P. (2016). Models of learning space: Integrating research on space, place and learning in higher education. Review of Education, 4(2), 149-191. https://doi.org/10.1002/ rev3.3056.

Fischer, F., Kollar, I., Stegmann, K., \& Wecker, C. (2013). Toward a script theory of guidance in computer-supported collaborative learning. Educational Psychologist, 48(1), 56-66. https://doi. org/10.1080/00461520.2012.748005.

Frank, A. J., \& Wilson, E. A. (2020). A Silvan Tomkins handbook: Foundations for affect theory. Minneapolis, MN: University of Minnesota Press. https://doi.org/10.5749/9781452965802.

Furján, H. (2007). Design/research: Notes on a manifesto. Journal of Architectural Education, 61(1), 62-68. https://doi.org/10.1111/j.1531-314x.2007.00129.x.

Garip, G., Seneviratne, S. R., \& Iacovou, S. (2020). Learners' perceptions and experiences of studying psychology online. Journal of Computers in Education. https://doi.org/10.1007/s40692-020-00167 $-4$.

Gaynor, T. S., \& Wilson, M. E. (2020). Social vulnerability and equity: The disproportionate impact of COVID-19. Public Administration Review, 80(5), 832-838. https://doi.org/10.1111/puar.13264. 
Graham, C. R. (2006). Blended learning systems. In The handbook of blended learning: Global perspectives, local designs (pp. 3-21). San Francisco: Wiley.

Green, W., Anderson, V., Tait, K., \& Tran, L. T. (2020). Precarity, fear and hope: Reflecting and imagining in higher education during a global pandemic. Higher Education Research and Development, 39(7), 1309-1312. https://doi.org/10.1080/07294360.2020.1826029.

Harding, A., Kaczynski, D., \& Wood, L. (2012, October). Evaluation of blended learning: Analysis of qualitative data. In Proceedings of the Australian conference on science and mathematics education (formerly UniServe science conference, p. 11).

Hasan, N., \& Bao, Y. (2020). Impact of "e-Learning crack-up" perception on psychological distress among college students during COVID-19 pandemic: A mediating role of "fear of academic year loss." Children and Youth Services Review, 118, 105355. https://doi.org/10.1016/j.childyouth .2020.105355.

Heidegger, M. (1962). Being and time (trans: Macquarrie, J., \& Robinson, E.). Hoboken, NJ: Blackwell Publishers Ltd.

Hodges, C., Moore, S., Lockee, B., Trust, T., \& Bond, A. (2020). The difference between emergency remote teaching and online learning. Educause Review, 27. https://er.educause.edu/articles/2020/3/ the-difference-between-emergency-remote-teaching-and-online-learning.

Hobbs, T. D., \& Hawkins, L. (2020). The results are in for remote learning: It didn't work. The Wall Street Journal.

Jæger, M. M., \& Blaabæk, E. H. (2020). Inequality in learning opportunities during COVID-19: Evidence from library takeout. Research in Social Stratification and Mobility, 68, 100524. https://doi. org/10.1016/j.rssm.2020.100524.

Jebakumar, C. (2009). A study of virtual learning environment with reference to the perceived preparedness of the college students in Tamil Nadu (South India). SSRN Electronic Journal. https://doi. org/10.2139/ssrn. 1553656 .

Jena, P. K. (2020). Impact of Pandemic COVID-19 on education in India. International Journal of Current Research. https://doi.org/10.31235/osf.io/2kasu.

Kapasia, N., Paul, P., et al. (2020). Impact of lockdown on learning status of undergraduate and postgraduate students during COVID-19 pandemic in West Bengal, India. Children and Youth Services Review, 116, 105194. https://doi.org/10.1016/j.childyouth.2020.105194.

Kollar, I., Pilz, F., \& Fischer, F. (2014). Why it is hard to make use of new learning spaces: A script perspective. Technology, Pedagogy and Education, 23(1), 7-18. https://doi.org/10.1080/14759 39x.2013.841615.

Lai, M., Lam, K. M., \& Lim, C. P. (2016). Design principles for the blend in blended learning: A collective case study. Teaching in Higher Education, 21(6), 716-729. https://doi.org/10.1080/13562 517.2016.1183611.

Laverty, S. M. (2003). Hermeneutic phenomenology and phenomenology: A comparison of historical and methodological considerations. International Journal of Qualitative Methods, 2(3), 21-35. https ://doi.org/10.1177/160940690300200303.

Lockee, B. B. (2020). Shifting digital, shifting context: (Re)considering teacher professional development for online and blended learning in the COVID-19 era. Educational Technology Research and Development. https://doi.org/10.1007/s11423-020-09836-8.

Macedo-Rouet, M., Ney, M., Charles, S., \& Lallich-Boidin, G. (2009). Students' performance and satisfaction with Web vs. paper-based practice quizzes and lecture notes. Computers and Education, 53(2), 375-384. https://doi.org/10.1016/j.compedu.2009.02.013.

Massey, D. (1999). Space-time, 'science' and the relationship between physical geography and human geography. Transactions of the Institute of British Geographers, 24(3), 261-276. https://doi.org/10.1 111/j.0020-2754.1999.00261.x.

Mastel-Smith, B., \& Stanley-Hermanns, M. (2012). "It's like we're grasping at anything" caregivers' education needs and preferred learning methods. Qualitative Health Research, 22(7), 1007-1015. https ://doi.org/10.1177/1049732312443739.

Merleau-Ponty, M. (1962). Phenomenology of perception (trans: Smith, C.). London: Routledge.

Mehra, V., \& Omidian, F. (2011). Examining students' attitudes towards e-learning: A case from India. Malaysian Journal of Educational Technology, 11(2), 13-18.

Melhuish, C. (2011). Methods for understanding the relationships between learning and space. In Re-shaping learning: A critical reader (pp 19-31). Brill Sense. https://doi. org/10.1007/978-94-6091-609-0_2. 
Moustakas, C. (2011). Research design and methodology. In Heuristic research: Design, methodology, and applications (pp. 38-58). https://doi.org/10.4135/9781412995641.d21.

Murphy, M. P. (2020). COVID-19 and emergency eLearning: Consequences of the securitization of higher education for post-pandemic pedagogy. Contemporary Security Policy. https://doi. org/10.1080/13523260.2020.1761749.

Poelmans, S., \& Wessa, P. (2015). A constructivist approach in a blended e-learning environment for statistics. Interactive Learning Environments, 23(3), 385-401. https://doi.org/10.1080/10494 820.2013.766890.

Raheja, G., \& Suryawanshi, S. (2014). Inclusive strategies for universal access in educational campus environments. In Inclusive designing (pp. 165-174). Springer. https://doi.org/10.1007/9783-319-05095-9_15.

Rashid, S., \& Yadav, S. S. (2020). Impact of COVID-19 Pandemic on higher education and research. Indian Journal of Human Development, 14(2), 340-343. https://doi.org/10.1177/0973703020 946700 .

Saltmarsh, S., Chapman, A., Campbell, M., \& Drew, C. (2015). Putting "structure within the space": Spatially un/responsive pedagogic practices in open-plan learning environments. Educational Review, 67(3), 315-327. https://doi.org/10.1080/00131911.2014.924482.

Sarin, S., \& Dholakia, N. (2016). Higher education in India at a crossroads: The imperative for transcending stagnation and embracing innovation. In (Re) discovering university autonomy (pp. 55-72). Palgrave Macmillan. https://doi.org/10.1057/9781137388728_4.

Schultz, R. B., \& DeMers, M. N. (2020). Transitioning from emergency remote learning to deep online learning experiences in geography education. Journal of Geography, 119(5), 142-146. https://doi.org/10.1080/00221341.2020.1813791.

Sepulveda-Escobar, P., \& Morrison, A. (2020). Online teaching placement during the COVID-19 pandemic in Chile: Challenges and opportunities. European Journal of Teacher Education, 43(4), 587-607. https://doi.org/10.1080/02619768.2020.1820981.

Smith, J. A., \& Shinebourne, P. (2012). Interpretative phenomenological analysis. American Psychological Association. https://doi.org/10.1037/13620-005.

Smith, J. A., \& Osborn, M. (2015). Interpretative phenomenological analysis as a useful methodology for research on the lived experience of pain. British Journal of Pain, 9(1), 41-42. https://doi. org/10.1177/2049463714541642.

Symeonides, R., \& Childs, C. (2015). The personal experience of online learning: An interpretative phenomenological analysis. Computers in Human Behavior, 51, 539-545. https://doi. org/10.1016/j.chb.2015.05.015.

Temple, P. (2008). Learning spaces in higher education: An under-researched topic. London Review of Education, 6(3), 229-241. https://doi.org/10.1080/14748460802489363.

Trung, T., Hoang, A. D., Nguyen, T. T., Dinh, V. H., Nguyen, Y. C., \& Pham, H. H. (2020). Dataset of Vietnamese student's learning habits during COVID-19. Data in Brief. https://doi.org/10.1016/j. dib.2020.105682.

Tuohy, D., Cooney, A., Dowling, M., Murphy, K., \& Sixsmith, J. (2013). An overview of interpretive phenomenology as a research methodology. Nurse Researcher. https://doi.org/10.7748/nr201 3.07.20.6.17.e315.

Williamson, B., Eynon, R., \& Potter, J. (2020). Pandemic politics, pedagogies and practices: Digital technologies and distance education during the coronavirus emergency. Learning, Media and Technology, 45(2), 107-114. https://doi.org/10.1080/17439884.2020.1761641.

Wong, L., Tatnall, A., \& Burgess, B. (2014). A framework for investigating blended learning effectiveness. Education and Training, 56(2), 233-251. https://doi.org/10.1108/et-04-2013-0049.

Wong, K. T., Hwang, G. J., Choo Goh, P. S., \& Mohd Arrif, S. K. (2020). Effects of blended learning pedagogical practices on students' motivation and autonomy for the teaching of short stories in upper secondary English. Interactive Learning Environments, 28(4), 512-525. https://doi. org/10.1080/10494820.2018.1542318.

Publisher's Note Springer Nature remains neutral with regard to jurisdictional claims in published maps and institutional affiliations. 
Dishari Chattaraj is an Assistant Professor in the Department of English and Cultural Studies at the School of Arts and Humanities in Christ University Bangalore. She has a PhD in Linguistics from Jawaharlal Nehru University, New Delhi, India and has been hosted as a Fulbright Fellow in Indiana University Bloomington, the USA (2019-2020). Her area of specialization being language teaching and learning, she seeks to promote an inclusive learning environment through her research and teaching endeavours.

Arya Parakkate Vijayaraghavan is an Assistant Professor in the Department of English and Cultural Studies at the School of Arts and Humanities in Christ University Bangalore. She has a PhD in English (Commonwealth Literatures) from The English and Foreign Languages University, Hyderabad, India. She aspires to translate the knowledge acquired through her research and teaching experiences in the areas of Women and Gender Studies, Postcolonial Studies, Cultural Studies, and English Language Education to understand the nature, politics, and relevance of academia in the contemporary times. 